\title{
Authors' Reply to Letter to the Editor: Continued improvement to genetic diversity indicator for CBD
}

\author{
Linda Laikre ${ }^{1} \cdot$ Paul A. Hohenlohe ${ }^{2} \cdot$ Fred W. Allendorf $^{3} \cdot$ Laura D. Bertola $^{4} \cdot$ Martin F. Breed $^{5} \cdot$ Michael W. Bruford $^{6}$. \\ W. Chris Funk ${ }^{7}$. Gonzalo Gajardo ${ }^{8}$. Antonio González-Rodríguez ${ }^{9}$ Catherine E. Grueber ${ }^{10}$. Philip W. Hedrick ${ }^{11}$. \\ Myriam Heuertz ${ }^{12} \cdot$ Margaret E. Hunter $^{13} \cdot$ Kerstin Johannesson $^{14} \cdot$ Libby Liggins $^{15} \cdot$ Anna J. MacDonald $^{16}$. \\ Joachim Mergeay ${ }^{17,18} \cdot$ Farideh Moharrek $^{19,20} \cdot$ David O'Brien $^{21} \cdot$ Rob Ogden $^{22} \cdot$ Pablo Orozco-terWengel $^{6}$. \\ Clarisse Palma-Silva ${ }^{23}$. Jennifer Pierson ${ }^{24}$. Ivan Paz-Vinas ${ }^{25}$. Isa-Rita M. Russo ${ }^{6}$. Nils Ryman ${ }^{1}$. \\ Gernot Segelbacher ${ }^{26} \cdot$ Per Sjögren-Gulve ${ }^{27} \cdot$ Lisette P. Waits ${ }^{28} \cdot$ Cristiano Vernesi $^{29} \cdot$ Sean Hoban ${ }^{30}$
}

Accepted: 24 March 2021 / Published online: 22 April 2021

(c) The Author(s) 2021

We appreciate the encouraging response to our call for indicators for genetic diversity within the post-2020 Global Biodiversity Framework of the Convention on Biological Diversity, CBD (Laikre et al. 2020; Hoban et al. 2020). In agreement with us, Frankham (2021) highlights the urgent necessity for the CBD to include an indicator that tracks the maintenance of genetic diversity within populations of all species—wild and domestic. Draft CBD Headline indicators

This reply refers to the comment available online at https://doi.org/ 10.1007/s10592-021-01357-y.

Linda Laikre

linda.laikre@popgen.su.se

Sean Hoban

shoban@mortonarb.org

Paul A. Hohenlohe

hohenlohe@uidaho.edu

Fred W. Allendorf

fred.allendorf@gmail.com

Laura D. Bertola

laura.bertola@gmail.com

Martin F. Breed

martin.breed@flinders.edu.au

Michael W. Bruford

BrufordMW@Cardiff.ac.uk

W. Chris Funk

Chris.Funk@ colostate.edu

Gonzalo Gajardo

ggajardo@ulagos.cl

Antonio González-Rodríguez

agrodrig@iies.unam.mx (which all CBD Parties will need to report) do not include genetic diversity within populations of wild species (CBD/ SBSTTA/24/3Add.1).

The genetically effective population size $\left(N_{\mathrm{e}}\right)$ is a metric that quantifies the rate of genetic change within a population. We welcome Frankham's (2021) comments on the relevance of this important parameter, and the appropriate indicator threshold $\left(N_{\mathrm{e}}>500\right.$ or $N_{\mathrm{c}}>5000 ; N_{\mathrm{c}}=$ adult census size, the
Catherine E. Grueber

catherine.grueber@sydney.edu.au

Philip W. Hedrick

PHILIP.HEDRICK@asu.edu

Myriam Heuertz

myriam.heuertz@inrae.fr

Margaret E. Hunter

mhunter@usgs.gov

Kerstin Johannesson

Kerstin.Johannesson@gu.se

Libby Liggins

L.Liggins@massey.ac.nz

Anna J. MacDonald

anna.macdonald@anu.edu.au

Joachim Mergeay

joachim.mergeay@inbo.be

Farideh Moharrek

farideh.moharrek@sund.ku.dk

David O'Brien

David.OBrien@nature.scot

Rob Ogden

Rob.Ogden@ed.ac.uk 
Pablo Orozco-terWengel

orozco-terwengelpa@cardiff.ac.uk

Clarisse Palma-Silva

clarissepalma@gmail.com

Jennifer Pierson

Jennifer.Pierson@australianwildlife.org

Ivan Paz-Vinas

ivanpaz23@gmail.com

Isa-Rita M. Russo

russoim@cardiff.ac.uk

Nils Ryman

nils.ryman@popgen.su.se

Gernot Segelbacher

gernot.segelbacher@wildlife.uni-freiburg.de

Per Sjögren-Gulve

Per.Sjogren-Gulve@ naturvardsverket.se

Lisette P. Waits

lwaits@uidaho.edu

Cristiano Vernesi

cristiano.vernesi@fmach.it

1 Division of Population Genetics, Department of Zoology, Stockholm University, SE 10691 Stockholm, Sweden

2 Institute for Bioinformatics and Evolutionary Studies, Department of Biological Sciences, University of Idaho, 875 Perimeter Drive MS 3051, Moscow, ID 83844-3051, USA

3 Division of Biological Sciences, University of Montana, Missoula, MT 59812, USA

4 City College of New York, 160 Convent Ave., New York, NY 10031, USA

5 College of Science and Engineering, Flinders University, Bedford Park, SA 5042, Australia

6 School of Biosciences, Cardiff University, Cardiff CF10 3AX, Wales, UK

7 Graduate Degree Program in Ecology, Department of Biology, Colorado State University, Fort Collins, CO, USA

8 Universidad de Los Lagos, Lab Genetics, Aquaculture \& Biodiversity, Osorno, Chile

9 Instituto de Investigaciones en Ecosistemas y Sustentabilidad, Universidad Nacional Autónoma de México, Morelia, Michoacán, Mexico

10 School of Life and Environmental Sciences, Faculty of Science, The University of Sydney, Sydney, NSW 2006, Australia

11 School of Life Sciences, Arizona State University, Tempe, AZ 85287, USA
12 INRAE, Univ. Bordeaux, Biogeco, 69 route d'Arcachon, 33610 Cestas, France

13 U.S. Geological Survey, Wetland and Aquatic Research Center, 7920 NW 71st St, Gainesville, FL 32653, USA

14 Department of Marine Sciences, University of Gothenburg, Tjärnö, Strömstad, Sweden

15 School of Natural and Computational Sciences, Massey University, Auckland, New Zealand

16 The John Curtin School of Medical Research/Research School of Biology, The Australian National University, Acton, ACT 2601, Australia

17 Research Institute for Nature and Forest, Gaverstraat 4, 9500 Geraardsbergen, Belgium

18 Aquatic Ecology, Evolution and Conservation, KULeuven, Charles Deberiotstraat 32, box 2439, 3000 Leuven, Belgium

19 Novo Nordisk Foundation Center for Basic Metabolic Research, Faculty of Health and Medical Sciences, University of Copenhagen, Blegdamsvej 3B, 2200 Copenhagen, Denmark

20 Faculty of Biological Sciences, Tarbiat Modares University, Tehran 14115-154, Iran

21 Scottish Natural Heritage, Leachkin Road, Inverness IV3 8NW, UK

22 Royal (Dick) School of Veterinary Studies and the Roslin Institute, University of Edinburgh, Easter Bush Campus, EH25 9RG Midlothian, UK

23 Department of Plant Science, Institute of Biology, University of Campinas, Campinas, SP 13083-862, Brazil

24 Australian Wildlife Conservancy, PO Box 8070, Subiaco East WA 6008, Australia

25 Laboratoire Evolution \& Diversité Biologique, Centre National pour la Recherche Scientifique, Institut de Recherche pour le Développement, Université Toulouse III Paul Sabatier, UMR-5174 EDB, Toulouse, 118 route de Narbonne, 31062 Toulouse, France

26 Wildlife Ecology and Management, University Freiburg, Tennenbacher Str. 4, 79106 Freiburg, Germany

27 The Wildlife Analysis Unit, The Swedish Environmental Protection Agency, 10648 Stockholm, Sweden

28 Department of Fish and Wildlife Sciences, University of Idaho, Moscow, ID 83844, USA

29 Department of Sustainable Agroecosystems and Bioresources, Research and Innovation Centre - Fondazione Edmund Mach, via E. Mach 1, 38010 S. Michele All'Adige, TN, Italy

30 Center for Tree Science, The Morton Arboretum, 4100 Illinois Rt 53, Lisle 60532, USA 
number of sexually mature individuals). Frankham (2021) suggests rewording our proposed indicator 1, "The number of populations [or breeds] within species with an effective population size $>500$ compared to the number $<500$ ", to "The number of populations (or breeds) with $>5000$ mature individuals compared to the number $<5000$." The proposed rephrasing coincides with our suggestion that in the absence of empirical knowledge on $N_{\mathrm{e}}$, the relationship $N_{\mathrm{e} /} N_{\mathrm{c}} \approx 0.1$ can be assumed, substituting $N_{\mathrm{c}} \approx 5000$ for $N_{\mathrm{e}} \approx 500$ (Fig. 1). We included published estimates of $N_{\mathrm{e}}$ from many populations (Hoban et al. 2020, 2021), recognizing they were not always directly comparable depending on methods used; we appreciate Frankham's examination of subsets of estimates, which also supports a ratio of approximately 0.1 for many species.

Frankham (2021) proposes that his wording is simpler and more suitable for a policy audience. We agree that $N_{\mathrm{e}}$ may be conceptually challenging, but we remain convinced that, even if $N_{\mathrm{c}}>5000$ will often be used as a proxy, the term "genetically effective population size" has important meaning in policy (including the CBD, the EU Biodiversity Strategy, and others) for several reasons:

(1) $N_{\mathrm{e}}$ stresses that within-population genetic diversity is the indicator's focus. We consider it critical to signal to policy makers that census size $N_{\mathrm{c}}$ is not a sufficient metric to track how fast a population loses genetic diversity. The recent CBD document CBD/SBSTTA/24/3Add.2 acknowledges this: "While population abundance is a key factor in the maintenance of genetic diversity, it is not a sufficient indicator since it does not account for within-population genetic diversity".

(2) Including $N_{\mathrm{e}}$ could spur CBD Parties to initiate more genetic monitoring efforts that will increase availability of robust estimates of $N_{\mathrm{e}}$ or taxon-specific $N_{\mathrm{e}} / N_{\mathrm{c}}$ ratios. Also, $N_{\mathrm{e}}$ estimates should rapidly increase with the broadening availability of genomic and bioinformatics resources and large-scale databases (Santiago et al. 2020; Lawrence et al. 2019).

(3) The CBD has used $N_{\mathrm{e}}$ concepts since it first included threatened animal breeds as an indicator. Livestock breeds have been considered as threatened or endangered based on $N_{\mathrm{e}}$ thresholds since at least 1992, when $N_{\mathrm{e}}<200$ was used to signal genetic erosion (Maijala 1992). $N_{\mathrm{e}}$ features prominently and is explained in detail in numerous Food and Agriculture Organization manuals, and the US endangered species recovery planning, the zoo community, and others are also already utilizing $N_{\mathrm{e}}$ for monitoring genetic diversity.

(4) Although $N_{\mathrm{e}} / N_{\mathrm{c}} \approx 0.1$ is an appropriate general estimate, Frankham and we ourselves are mindful that there is substantial variation; Frankham et al. (2019) provide a thorough analysis in this context. The indicator $N_{\mathrm{e}}>500$ represents a reminder that maintaining genetic diversity within populations can sometimes require smaller or larger census sizes than $N_{\mathrm{c}}=5000$, and allows the use of adequate $N_{\mathrm{e}} / N_{\mathrm{c}}$ estimates when available.

(5) $N_{\mathrm{c}}$ can be even more difficult to estimate than $N_{\mathrm{e}}$, e.g. in many mobile, nocturnal, subterranean, or otherwise hard to count organisms.

Frankham (2021) rightly states that $N_{\mathrm{e}}$ can be complex, but theoretical developments and simulated and empirical data are consistently improving our knowledge and tools (Hössjer et al. 2016; Wang 2016; Ryman et al. 2019; Santiago et al. 2020). Our approach allows new information to be used to adjust $N_{\mathrm{e}} / N_{\mathrm{c}}$. In addition, the relationship between ploidy level and loss of diversity is likely not as straightforward as suggested by Frankham. For example,
Fig. 1 Conceptual diagram for applying the $N_{\mathrm{e}}$ indicator (Hoban et al. 2020). If direct and robust estimates of $N_{\mathrm{e}}$ are available, they should be used. If only general information is available about factors affecting the ratio of $N_{\mathrm{e}}$ to census population size $\left(N_{\mathrm{c}}\right)$, then this information should be used to calibrate estimates of $N_{\mathrm{c}}$ from the specific population against the $N_{\mathrm{e}}>500$ threshold. If no information is available, the indicator is applied using estimates of $N_{\mathrm{c}}$ with the threshold $N_{\mathrm{c}}>5000$, implicitly assuming $N_{\mathrm{e}} / N_{\mathrm{c}}=0.1$

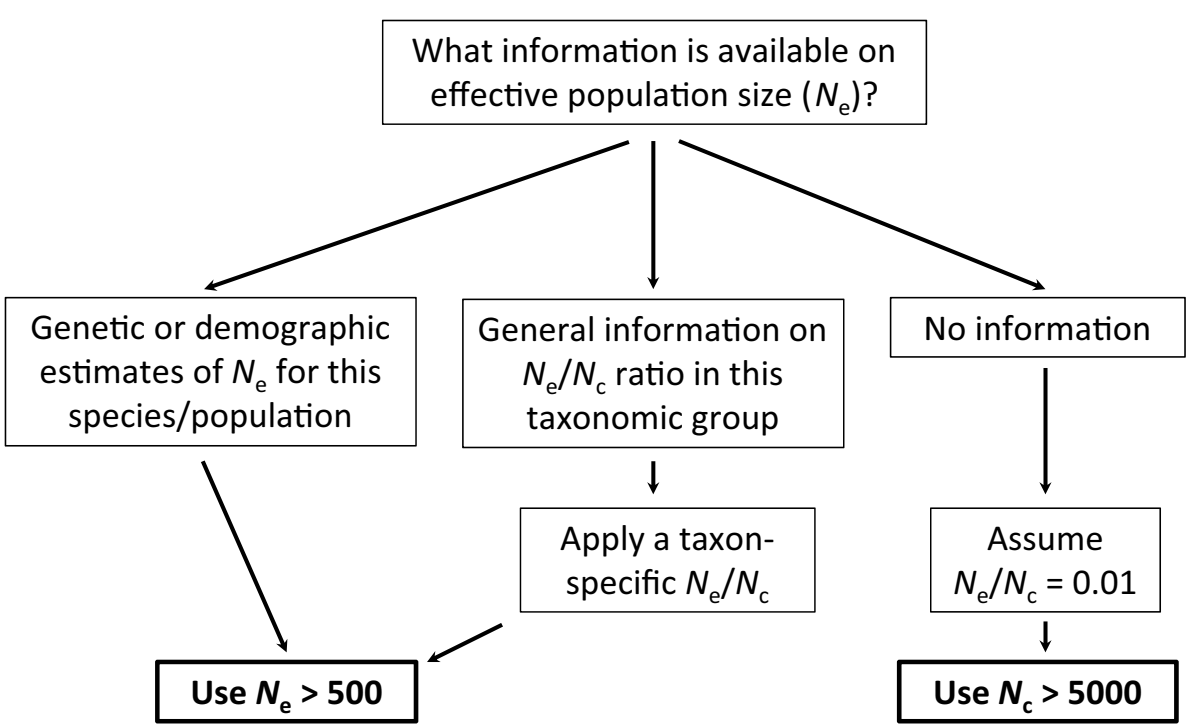


approximately $50 \%$ of all plant species are polyploids, and most, but not all, polyploids lose diversity at the same rate $\left(1 / 2 N_{\mathrm{e}}\right)$ as diploids (Soltis and Soltis 2000).

Conservation geneticists worldwide are working together to rapidly provide science-based guidelines for Goals, Targets, and Indicators for the post-2020 CBD framework. The Species Information Centre at the Swedish University of Agricultural Sciences has agreed to test indicators 1 and 2 (Hoban et al. 2020) on taxa from the Swedish Red List, and a G-BiKE (https://sites.google.com/fmach.it/g-bike-geneticseu/home) working group is compiling data on indicator 3 . We look forward to collaborating with Frankham and others to achieve improved CBD indicators for genetic diversity. Genetic diversity must be conserved as a foundation for all biodiversity, adaptive potential, resilience and nature's contributions to society.

Acknowledgments We acknowledge ongoing collaboration with the GEO BON Genetic Composition Working Group, the IUCN Conservation Genetics Specialist Group, the Society for Conservation Biology Conservation Genetics Working Group, and the EU Cost Action Genomic Biodiversity Knowledge for Resilient Ecosystems (G-BiKE). This publication is based upon work from COST Action G-BiKE, supported by COST (European Cooperation in Science and Technology). VR and Formas supported L.L. Any use of trade, firm, or product names is for descriptive purposes only and does not imply endorsement by the United States Government.

Open Access This article is licensed under a Creative Commons Attribution 4.0 International License, which permits use, sharing, adaptation, distribution and reproduction in any medium or format, as long as you give appropriate credit to the original author(s) and the source, provide a link to the Creative Commons licence, and indicate if changes were made. The images or other third party material in this article are included in the article's Creative Commons licence, unless indicated otherwise in a credit line to the material. If material is not included in the article's Creative Commons licence and your intended use is not permitted by statutory regulation or exceeds the permitted use, you will need to obtain permission directly from the copyright holder. To view a copy of this licence, visit http://creativecommons.org/licenses/by/4.0/.

\section{References}

Frankham R (2021) Suggested improvements to proposed genetic indicator for CBD. Conserv Genet. https://doi.org/10.1007/ s10592-021-01357-y

Frankham R, Ballou JD, Ralls K et al (2019) A practical guide for genetic management of fragmented animal and plant populations. Oxford University Press, Oxford (online Appendix 2). http://www. oup.co.uk/companion/FrankhamPG

Hoban S, Bruford M, D’Urban Jackson J et al (2020) Genetic diversity targets and indicators in the CBD post-2020 Global Biodiversity Framework must be improved. Biol Conserv 248:108654

Hoban S, Paz-Vinas I, Aitken S et al (2021) Effective population size remains a suitable, pragmatic indicator of genetic diversity for all species, including forest trees. Biol Conserv 253:108906

Hössjer O, Laikre L, Ryman N (2016) Effective sizes and time to migration-drift equilibrium in geographically subdivided populations. Theor Popul Biol 112:139-156

Laikre L, Hoban S, Bruford MW et al (2020) Post-2020 goals overlook genetic diversity. Science 367:1083-1085

Lawrence ER, Benavente JN, Matte J-M et al (2019) Geo-referenced population-specific microsatellite data across American continents, the MacroPopGen Database. Sci Data 6:14. https://doi. org/10.1038/s41597-019-0024-7

Maijala K (1992) Monitoring animal genetic resources and criteria for prioritization of breeds. FAO Animal Production and Health Paper (FAO)

Ryman N, Laikre L, Hössjer O (2019) Do estimates of contemporary effective population size tell us what we want to know? Mol Ecol 28:1904-1918

Santiago E, Novo I, Pardiñas AF et al (2020) Recent demographic history inferred by high-resolution analysis of linkage disequilibrium. Mol Biol Evol 37:3642-3653

Soltis P, Soltis D (2000) The role of genetic and genomic attributes in the success of polyploids. Proc Natl Acad Sci USA 97:7051-7057

Wang J (2016) A comparison of single-sample estimators of effective population sizes from genetic marker data. Mol Ecol $25: 4692-4711$

Publisher's Note Springer Nature remains neutral with regard to jurisdictional claims in published maps and institutional affiliations. 